Journal homepage: http://revistas.unap.edu.pe/rd/ E-mail: revistaderecho@unap.edu.pe

\title{
LA DONACIÓN ENTRE VIVOS Y EL DESPLAZAMIENTO DEL
}

\section{TESTAMENTO}

\author{
Eva Marina Centeno Zavala *
}

\section{INFORMACIÓN DEL ARTÍCULO}

Art. Recibido: 01/10/2019

Art. Aceptado: 04/11/2019

Art. Publicado: 30/12/2019

* Universidad Nacional del Altiplano, Facultad de Ciencias Jurídicas y Políticas, Jr. Grau esq. Conde Lemus. Puno, Perú, mcentenoz@hotmail.com 
Journal homepage: http://revistas.unap.edu.pe/rd/ E-mail: revistaderecho@unap.edu.pe

\title{
RESUMEN:
}

El trabajo de investigación, se desarrolla desde una perspectiva de la realidad social que se fue desplazando una institución tan importante como es el Testamento, y en la realidad cotidiana se recurre a la simulación que consiste en optar por la donación entre vivos. La investigación teniendo como objetivo central de conocer las causas y consecuencias, como el grado de preferencia de gente al optar por la donación entre vivos y no acudir a la transmisión de herencia vía los testamentos. La investigación se trabaja bajo la metodología cualitativa de tipo Jurídico - Explicativo y Sociológico, teniendo un proceso rígido de recolección de datos que consta de análisis documental longitudinal, abarcando los últimos 15 años a la presente investigación, llegando a los resultados que la donación entre vivos se ha intensificado cuyas causas son las necesidades inmediatas de los hijos llegando a la simulación de ventas, esto trae consecuencias de desnaturalizar la institución llamada sucesiones.

Palabras Claves: Derecho sucesorio. Testamento. Causante. Donación entre vivos. Derecho Civil. Realidad apremiante. Labor Notarial y Registral. Simulación. Herencia. Transmisión de bienes.

\begin{abstract}
:
The research work is developed from a perspective of social reality that was displaced by an institution as important as the Testament, and in everyday reality the simulation that consists in opting for living donation is used. The research with the main objective of knowing the causes and consequences, such as the degree of preference of people when opting for donation among the living and not resorting to the transmission of inheritance via wills. The research is carried out under the qualitative methodology of Legal - Explanatory and Sociological type, having a rigid process of data collection that consists of longitudinal documentary analysis, covering the last 15 years to the present investigation, reaching the results that the donation between living It has intensified whose causes are the immediate needs of the children reaching the sales simulation, this brings consequences of denaturing the institution called successions.
\end{abstract}

Keywords: Succession law. Will. Causative. Donation between the living. Civil law. Reality pressing. Notary and Registral. Simulation. Heritage. Transmission of goods. 
Journal homepage: http://revistas.unap.edu.pe/rd/ E-mail: revistaderecho@unap.edu.pe

\section{INTRODUCCIÓN}

El presente artículo de "Donación entre vivos y el desplazamiento del Testamento" tiene una vinculación directa con nuestra realidad social que es la que finalmente en su dinámica muestra la eficacia o no de las normas legales. Es así que las personas prefieren destinar mediante la donación llamada entre vivos su patrimonio en vez de optar por la vía de la sucesión testamentaria, y tampoco por la sucesión intestada. Por lo tanto frente a esta realidad que de modo fáctico se suscita en nuestra realidad resulta preocupante que exista un desplazamiento del testamento que de modo tradicional siempre ha sido la vía más preferida para realizar la transmisión del patrimonio de tipo familiar. Por lo que detectado el problema, nos proponemos en este trabajo señalar sus probables causas, así como plantear alternativas de solución, recalando en los cambios o modificaciones que debe existir en nuestra normatividad civil al respecto, y principalmente que sea acorde a la realidad social en que vivimos.

Se ha optado por escoger el tipo de método de investigación que es de carácter cualitativo, así como se ha planteado objetivos que tienen que ver con las causas, consecuencias y alternativas de solución, así mismo, se ha planteado un marco teórico que permite conocer la fundamentación doctrinal de lo que son testamentos, donación la labor notarial y la dinámica social. (Arias ,1996) Por otro lado en el aspecto metodológico, es un trabajo que tiene que ver con el análisis de normas, así como de interpretar nuestra realidad social en términos de la idiosincrasia o criterios convencionales que tienen las familias peruanas hoy en día. El cómo del presente trabajo, tiene que ver con los medios establecidos para una tesis cualitativa (Ramos, 2001)

Finalmente, se trata de aportar situaciones de cambio en nuestra normatividad civil, venidas de las formas o manifestaciones sociales, que en ésta materia se vienen configurando de una manera intensa y mayoritaria en la elección de la donación entre vivos y el desplazamiento de la figura de la sucesión testamentaria, tal como lo advertía en su trabajo (Armaza, 2001).

\section{MATERIALES Y MÉTODOS.}

La investigación no tiene ámbito específico de investigación, pues, por las características de las unidades materia de análisis se contextualiza en el territorio nacional y la región de Puno. El tiempo es longitudinal y abarca los últimos 15 años

En las variables independientes se tomó como dimensiones al Estado y Sociedad, Normas Jurídicas, Acción del Notariado; Asimismo para la variable se toma las dimensiones como Donación entre vivos, Ineficiencia del Testamento y Transmisión de la Herencia.

\section{Técnicas e Instrumentos}

Las técnicas a aplicarse en el presente investigación fue la técnica de la observación analítica documental mediante la indagación que consiste en la ubicación, revisión y análisis de la información documentada existentes sobre la denominada "Donación entre vivos" que se manifiestan en nuestro país y en la región Puno. 


\section{RESULTADOS Y DISCUSION.}

La recurrencia de distorsionar la legalidad (Alexy, 1993) para favorecer en el presente caso con el sentido de la sucesión es lo que constituye el problema, y a la vez el centro neurálgico del presente artículo. Uno de los temas es que dicha recurrencia se configura a través de la simulación, y es por ello ampliar la visión de esta figura, mostrar casos y finalmente los aspectos controversiales.

\section{E1 acuerdo simulatorio.}

Para que exista simulación es necesario el común acuerdo de todas las partes intervinientes, sobre lo que realmente quieren hacer en privado y lo que realmente quieren aparentar hacer en público

La palabra simulación proviene del latín simulare $=$ fingir, hacer aparecer una cosa distinta de la realidad. El Diccionario de la Lengua Española de la Real Academia define a la simulación como la "alteración aparente de la causa, la índole o el objeto verdadero de un acto o contrato". Agrega que simular es "representar una cosa fingiendo o imitando lo que no es". (Varios, 2005)

Simular, o fingir, o aparentar, importa mentir, ya porque se quiere ocultar (disimular), en todo o en parte, una verdad, ya porque se quiere hacer aparecer como verdad una falsedad, o ya porque se desea aparecer frente a terceros una verdad diversa de la efectiva, esto es, con una verdad aparente se disimula (se esconde) otra verdad real.( Legaz, 1979), apreciación relevante y de pura gnoseología.

En la vida diaria, por diversas razones, el ser humano simula, miente. Simula estar enfermo para no concurrir a una cita o para evitar un castigo, simula tener talento, carácter, conocimientos con el fin de acceder a un puesto de trabajo; disimula defectos, fracasos, vicios, enfermedades, etc. Muchos sujetos son unos verdaderos artistas en la escena de la vida.

En el ámbito de los actos jurídicos, la simulación es muy frecuente. Se usa para engañar a terceros con los más diversos fines; aparentar solvencia o insolvencia económica, defraudar a los acreedores, engañar a un pariente pedigüeño, eludir prohibiciones legales, protegerse contra la delincuencia, evitar herir susceptibilidades, evitar el pago de impuestos, beneficiar a unos hijos antes que a otros, facilitar la realización de ciertos negocios, etc.

El acto jurídico es simulado cuando las partes, con el fin de engañar a terceros, se han puesto de acuerdo (acuerdo simulatorio) para crearlo (o modificarlo o extinguirlo) con un valor aparente, destinado a no producir efectos entre ellas, sino solamente respecto a terceros, ya porque no quieren realizar acto jurídico real alguno, ya porque con la apariencia quieren ocultar la verdadera naturaleza o contenido del acto que celebran. (De la Puente, 1984) Por ejemplo, se simula realizar una compraventa, pero en realidad no se pretende vender ni comprar, o bien se pretende donar, se simula donar a Pedro cuando en realidad el donatario es Juan; se simula vender por 100 cuando el precio efectivo es de 150 . 
Journal homepage: http://revistas.unap.edu.pe/rd/ E-mail: revistaderecho@unap.edu.pe

La intención de los simulantes consiste: o bien en celebrar un acto jurídico meramente aparente que no tiene nada real, o bien en celebrar un acto real dándole una apariencia distinta para ocultarlo a la vista de los demás. (Bustamante, 2010). De lo que se deduce que hay simulación: a) cuando simplemente se crea un acto aparente que nada tiene de real; b) cuando se encubre la naturaleza jurídica de un acto bajo la apariencia de otro (ej., la donación se encubre bajo la apariencia de una venta); c) cuando el acto contiene fechas, precios u otras estipulaciones que no son verdaderas; d) cuando por él se constituyen o transmiten derechos a personas interpuestas ficticias, que no son aquellas para quienes en realidad se constituyen o transmiten.(Calderón, 2011)

Por la exigencia del acuerdo simulatorio se explica fácilmente que la simulación es posible solamente en los actos bilaterales o plurilaterales, en los cuales el acuerdo se lleva a cabo entre las partes que intervienen en el acto y en los actos unilaterales receptivos, en los que el acuerdo simulatorio se produce entre el autor de la declaración y el destinatario de la misma.( Arias, 1996)

\section{Doctrina que considera a la simulación como vicio de la causa del acto jurídico.}

Esta doctrina considera a la simulación como una de las anomalías estructurales del acto jurídico que incide sobre la causa entendida en su doble acepción: como la función social que el acto debe cumplir y como el fin práctico que las partes quieren alcanzar. En la simulación hay una divergencia entre la causa típica de la figura jurídica utilizada y la finalidad concreta que las partes quieren alcanzar. (Carrión, 2011) Las partes persiguen, a través del acto jurídico, un fin disimulado, distinto de su causa típica.

Expliquemos con un ejemplo: Si se concluye un contrato de compraventa real, la finalidad típica perseguida por los contratantes consiste en obtener una cantidad de dinero para el vendedor y adquirir la propiedad de un bien para el comprador (artículo 1529.C.C.); en cambio, si se celebra un contrato de compraventa simulada, el fin práctico perseguido por las partes no es el de obtener una cantidad de dinero o adquirir la propiedad de un bien a título oneroso, sino que puede consistir en sustraer el bien a la acción del acreedor del simulado vendedor, o evitar ser víctima de la delincuencia, o librarse de los requerimientos de terceros para que les transfiera el bien, o transferir el bien a título gratuito, etc. ( Santoro, 1964) En el acto simulado hay una causa fin ficticia (la causa típica) y una causa fin real (la finalidad concreta).

Los simulantes quieren y tienen conciencia del acto que realizan, pero lo usan solamente como instrumento para conseguir un fin diverso de aquél que constituye su causa típica. ( Forno, 1993) La finalidad real o subyacente puede afectar a la naturaleza del acto o a cualquiera de sus elementos: a las partes, al objeto, a las modalidades, a los gravámenes, etc. Esta finalidad subyacente es de índole diversa, por ejemplo, evitar la malsana curiosidad ajena, evitar que el acreedor realice los bienes de su deudor, favorecer con un acto de liberalidad a determinada persona, eludir una prohibición legal, evadir o reducir el pago de impuestos, etc. En efecto, nadie crea una apariencia de acto jurídico así porque sí, sin perseguir alguna finalidad, sino que lo hace con el propósito de obtener algún resultado específico. (Torres, 2002) La simulación, sea total o parcial, afecta siempre a la causa del acto jurídico. 
Journal homepage: http://revistas.unap.edu.pe/rd/ E-mail: revistaderecho@unap.edu.pe

\section{Efectos entre simulantes y terceros}

Recordemos quiénes son partes y quiénes terceros en un acto jurídico. Son partes los que intervienen en su celebración, por sí o mediante representante, constituyéndose una en sujeto activo y otra en sujeto pasivo de la relación jurídica creada, o de la relación preexistente modificada, regulada o extinguida.(Devis Echandía,1938)

Terceros son aquellos que no han tenido participación en la celebración del acto jurídico, ni por sí ni mediante representante, y, por consiguiente, no pueden gozar ni sufrir sus efectos. Los terceros y sus herederos no son parte, activa ni pasiva, de la relación jurídica creada con el acto jurídico (Castillo, 2007). Los terceros pueden ser absolutos o relativos. Los primeros no tienen relación jurídica de ninguna clase con los que son partes en el acto jurídico, por lo que sus efectos no les pueden tocar para nada; los terceros relativos son aquellos ajenos a las partes del acto jurídico, pero que pueden ser alcanzados, positivamente o negativamente, por sus efectos, por ejemplo, el comprador de un bien arrendado, si el arrendamiento está inscrito, debe respetar el contrato convenido por su vendedor con un tercero; el acreedor afectado por el acto de disposición realizado por su deudor con un tercero, puede impugnarlo vía acción pauliana, etc.

El testaferro tampoco es parte, sino tercero, de la relación jurídica creada con un acto simulado, desde que todos los derechos u obligaciones que recibe aparentemente, se reputan adquiridos directamente por la parte oculta, quien en realidad será la verdadera propietaria, poseedora, acreedora, deudora, etc. El prestanombre no es sujeto activo ni pasivo de la relación jurídica creada, o modificada o extinguida (Armaza, 2001)

Con referencia al acto simulado, los terceros relativos son los causahabientes de una de las partes del acto simulado. Ellos se distinguen en terceros adquirentes (de una de las partes simulantes) de derechos o garantías reales sobre los bienes materia del acto simulado y terceros acreedores. Los unos o los otros pueden ser adquirentes o acreedores del simulante enajenante (titular efectivo) o del simulante adquirente (titular aparente). En la simulación de persona, el titular aparente es el testaferro y el titular efectivo podrá ser o el enajenante (si la enajenación es inválida) o el adquirente disimulado (si la enajenación es válida).

Las relaciones entre simulantes y terceros se basan en el principio de la inoponibilidad de la simulación por los simulantes a los terceros de buena fe. La simulación, mientras no sea descubierta, es irrelevante para los terceros. Por principio, el acto simulado es válido y eficaz frente a los terceros. (Bragi,1946) Si la simulación es relativa, descorrido el velo que ocultaba el carácter real del acto, será indudablemente este carácter, antes oculto y ahora notorio, por el que se rigen no solamente las partes, sino también los terceros.

\section{Efectos entre simulantes y terceros adquirentes del titular aparente}

La simulación no puede ser opuesta por las partes ni por los terceros perjudicados a quien de buena fe y a título oneroso haya adquirido derecho del titular aparente.

La fuente es el artículo 1097 del C.C. de 1936 que dice: "Si la persona favorecida por la simulación ha trasferido a otro sus derechos, la acción contra el tercero será admisible si la trasmisión tuvo lugar a título gratuito. Si la transmisión se operó a título oneroso, la revocación solo será posible, si el sub-adquirente obró con mala fe".(Ibidém) 
Journal homepage: http://revistas.unap.edu.pe/rd/ E-mail: revistaderecho@unap.edu.pe

El tercero que adquiere derechos del titular aparente será de buena fe si al tiempo de la adquisición ignoraba la simulación, ni estaba en la posibilidad de conocerla observando una normal diligencia; caso contrario, es de mala fe. La buena fe se presume (se presume que el tercero adquirente no sabía de la simulación, ni podía conocerla) y quien la niegue debe probarla.

Cuando el tercero adquirente es de buena fe, hay que distinguir si la adquisición lo hizo a título oneroso o gratuito.

Ninguno de los simulantes, ni el titular aparente, ni el efectivo, ni sus herederos, ni sus acreedores, aunque estos resulten perjudicados, puede oponer la simulación a quien de buena fe y a título oneroso haya adquirido derechos del titular aparente. (Ferrara, 1926) Por el principio de seguridad jurídica, quien es causahabiente del titular aparente por haber adquirido, de buena fe y a título oneroso, derechos o garantías reales sobre los bienes que fueron objeto del acto simulado, está plenamente protegido por el beneficio de la inoponibilidad de la simulación, aun cuando el acto simulado haya sido declarado nulo.

La simulación en nuestro Código constituye pues un acto nulo o anulable, según fuere presumida por la ley, o el acto esté viciado de simulación. Conviene recordar que "la buena fe de los terceros" está protegida por nuestro Código Civil.

\section{Casos de simulación y de donación entre vivos.}

$\mathrm{Ej}$. "A" vende simuladamente un inmueble a "B" y este le otorga un contradocumento; y " $B$ " a su vez vende "a un tercer adquirente de buena fe", ese acto será válido, pues el contradocumento solo producirá efecto entre las partes y el propietario original " $\mathrm{A}$ ", no tendrá derecho a la acción repersecutoria y sí un crédito por daños y perjuicios emergentes del acto formalizado por B con el tercer adquirente de buena fe.

Ej. de Simulación relativa: La supuesta venta de la cosa por A, a B, cuando en realidad el acto es una "donación" encubierta, pero como A no tiene herederos forzosos, al disponer A de la totalidad de sus bienes, no habrá perjuicio legal para sus parientes y en consecuencia, ese acto no podrá ser anulado.-

Pero si simulo una DONACIÓN, haciéndolo aparecer como una VENTA, para eludir el pago de mi deuda, ese acto aparente configurará "una simulación absoluta y está sujeta a anulación", siempre que "el tercero" sea cómplice del supuesto del acto oneroso.

Es muy frecuente que los padres se planteen en algún momento de su vida transmitir ciertos bienes inmuebles a sus hijos. Su intención es transmitirles los bienes; con independencia, en principio, de cómo los transmitan. Normalmente me plantean: “¿cómo resulta más económico, por compraventa o por donación?".

En este momento, hay que advertir que si media precio, estamos ante una compraventa, mientras que si lo que pretenden es transmitirlo gratuitamente, la verdadera intención de ellos, es formalizar una donación. (Ferrero, 1985) Y si se formaliza una compraventa, hay que hacer constar en la escritura el modo de satisfacer el precio, si es en efectivo metálico, si por transferencia, cheque u otro título valor se deben acreditar los medios de pago.

Para poder asesorar debidamente, hay que enfocar la cuestión, no sólo desde el punto de partida, sino también desde las consecuencias de una u otra opción. En el supuesto de 
Journal homepage: http://revistas.unap.edu.pe/rd/ E-mail: revistaderecho@unap.edu.pe

que los hijos estén casados en régimen de gananciales, ¿para quién quiere que sea lo que le transmita: para su hijo sólo, o para el matrimonio?

En caso de donación al hijo, aunque esté casado en régimen de gananciales, lo donado es privativo del donatario (del hijo que adquiere).

Sin embargo, en el supuesto de compraventa, en principio sería ganancial (del matrimonio), porque las rentas del trabajo son gananciales y porque los bienes existentes en el matrimonio se presumen gananciales mientras no se acredite la privatividad. Y digo que "en principio" son gananciales porque hay formas de probar y lograr que lo adquirido mediante compraventa por un cónyuge en régimen de gananciales sea privativo. ( Armaza, Ibidém)

Así, si un cónyuge dispone de dinero privativo, porque se lo han donado por ejemplo, compra un bien y pretende que sea privativo, el cónyuge del adquirente debe acudir también al notario en el momento de la venta para "declarar" el carácter privativo del dinero con el que se está comprando (el bien sustituye al dinero privativo). No obstante, hay dos excepciones: no se puede hacer uso de la "privatividad por confesión" para burlar los derechos de los acreedores del confesante ni de los herederos forzosos; es decir, que si el matrimonio dispone de efectivo metálico y uno de los cónyuges tiene deudas, no cabe comprar a nombre del solvente y declarar que el dinero es de él para proteger los bienes adquiridos (evitando así el ser perseguidos por los acreedores del deudor), ya que de esta forma la confesión no produce efectos. Y lo mismo respecto de los herederos forzosos (hijos, padres y cónyuge en sus respectivos casos).

Distinto es que se acredite la propiedad exclusiva del dinero con el que se adquiere, mediante un documento público. Pongamos el caso de que yo recibo por herencia de mi padre treinta mil euros, se formaliza la escritura de herencia, e inmediatamente después, con el dinero recibido, compro ante notario una plaza de garaje. En este caso, como el dinero heredado era privativo, el garaje es también privativo. Debemos tener presente estas consecuencias.

\section{Formalizar compraventa o donación también acarrea otras consecuencias.}

Así, si los padres donan un bien, salvo que manifiesten lo contrario, lo donado se considera colacionable. Por otro lado, la donación se presume hecha siempre en fraude de acreedores, y no admite prueba en contrario

En estos momentos de dificultad económica, es frecuente que lo que determine una u otra opción sean los costes que acarrean las operaciones, pero hay que informarse de dónde nos puede llevar.

Lo cierto, lo que prima es la intención de reducir costos, sobre todo fiscales. Siempre que se formalicen en escritura pública ante notario, de modo que para el adquirente, en estos casos resulte más favorable fiscalmente la donación que la compraventa.

Fuera de esos supuestos - en España- en determinados territorios y aquellos en los que la donación está bonificada, suele resultar menor el tipo impositivo que se aplica a la compraventa que a la donación. Así, la compraventa tributa, según las comunidades autónomas entre el 7 y el 10\% dependiendo de la cuantía, mientras que en las donaciones a descendientes, el margen oscila entre el 7,65\% y el 34\%. 
Journal homepage: http://revistas.unap.edu.pe/rd/ E-mail: revistaderecho@unap.edu.pe

Ahora bien, si lo que verdaderamente pretendemos -y prácticamente hacemos- es una donación, y para ahorrar impuestos firmamos una escritura de venta, debe tenerse presente que el Tribunal Supremo (sentencia 11-01-2007, reiterada posteriormente) ha declarado la nulidad de la donación disimulada bajo la forma de compraventa, y exige para la validez de la donación que la escritura sea precisamente de donación, y no de compraventa. ( Cervantes, 2002)

El que transmite debe tributar en renta por la ganancia patrimonial, en su caso, y abonar al Ayuntamiento la conocida como "Plusvalía" en caso de venta, si es donación, la plusvalía municipal la debe pagar el adquirente.

Sí, aunque resulte curioso (no sólo en caso de venta, sino también cuando el padre dona a su hijo), además de reducir su patrimonio, tiene que tributar por la supuesta ganancia patrimonial. Es la llamada "Plusvalía del Donante". El porcentaje que se abona depende de la fecha de la adquisición y es menor cuántos más años haya sido propietario.

Pero es más, las ganancias patrimoniales derivadas de la compraventa puede compensarlas el vendedor con las minusvalías generadas durante ese ejercicio fiscal y los cuatro posteriores, mientras que no se admite actualmente esa compensación para el donante.

Sin embargo, la plusvalía municipal, es mayor en cuantos más años haya sido propietario, determinándose sobre la base del valor catastral.

En caso de transmisión mortis causa de determinados bienes (como la vivienda habitual), dado que actualmente no se somete a tributación la que se conoció como "plusvalía del fallecido", que los beneficios fiscales suelen ser mayores en el Impuesto de Sucesiones que en el de Donaciones, y que también suelen establecer beneficios fiscales los ayuntamientos en "Plusvalía Municipal", de no existir otras razones que justifiquen la transmisión entre vivos, lo más favorable fiscalmente es heredar, y si se pretende determinar los bienes que han de heredar cada uno de los hijos, lo más conveniente es otorgar ante notario un testamento particional. De optar por la donación no debe olvidarse que esta debe formalizarse necesariamente en escritura pública de donación; no valen documentos privados.

De formalizarse una compraventa, y probarse que en realidad hubo una donación (porque no se pagó precio), la oficina liquidadora correspondiente podrá girar la oportuna liquidación complementaria.

\section{Aspectos controversiales.}

En definitiva lo que se tiene es que por un lado tenemos en la figura de testamentos, aquellos llamados especiales que no se ajustan a la realidad social en que vivimos, y por lo tanto deben ser derogados. Por otro lado en el caso de los testamentos ordinarios, la figura de los testigos testamentarios está en desuso y complican el otorgamiento de lo9s testamentos, por la excesiva formalidad que está establecido por Ley, estas dificultades hacen que sean poco recurrible por parte de los usuarios a utilizar los tipos de testamentos establecidos por la Ley, ya que en un mundo caracterizado por el corto tiempo, por la simplificación, resulta obstaculizante y a veces adverso la recurrencia a la figura de testamentos que ello crea el escenario propicio para que se produzca recurrir a la Donación entre vivos y a las diversas formas de simulación. 
Journal homepage: http://revistas.unap.edu.pe/rd/ E-mail: revistaderecho@unap.edu.pe

Por otro lado tenemos, que es necesario una actualización de Nuestro Código Civil, a la luz del Derecho Comparado, puesto que como se ha pretendido demostrar en el presente trabajo, el derecho debe estar acorde a las realidades sociales, y una distorsión de nuestra realidad social ante la ley, es la recurrencia justamente de la donación entre vivos, que no se ajusta a la era informática y tecnológica que vivimos en el siglo XXI, y ese es el caso de la exigencia por ejemplo de que los testamentos por Escritura Pública deben ser redactados de puño y letra, lo que no es concordante con la realidad.

\section{CONCLUSIONES:}

1.- En los últimos años la recurrencia a optar por la donación entre vivos, se ha intensificado, a nivel nacional, puesto que los padres han visto una forma oportuna, directa y previsoria el de recurrir por simulación a esta figura y dejar de lado las formas testamentarias, como se solía recurrir hace algunos años. Estas donaciones y transferencias de inmuebles a través de la donación o compra venta ficticia, ha permitido que se desnaturalice la figura de la herencia una vez que el titular del bien o testador, fallezca y deje a sus herederos. A pesar de que existe la sucesión intestada que es la otra forma de que los herederos recurran una vez fallecido los padres a seguir un proceso sucesorio, ésta tampoco no es recurrible como lo es la donación entre vivos o transferencias en simulación de la propiedad inmueble.

2.- Las causas para que se recurre a la donación entre vivos, o la simulación de venta del bien inmueble, son básicamente: La de que la institución de los testamentos ha llegado a una crisis, ello implica que figuras como el albacea casi ya no existan en la actualidad. Por otro lado hay causas económicas, en este tiempo los hijos tienen necesidades más inmediatas y no pueden esperar hasta que el padre fallezca para poder acceder a la herencia. Así mismo como una tercera causa se tiene la cultura transgresora del peruano, que "hecha la ley hecha la trampa", es decir que se recurre a torcer la Ley, hacerla más acorde a sus intereses y necesidades.

3.- Las consecuencias que ocasiona este tipo de prácticas jurídicas, es que se desnaturaliza la institución llamada sucesiones, que desde el Derecho Romano, cumplía la función de preservar generacionalmente los bienes en línea recta de padres a hijos. Por otro lado, se incumple la Ley, es decir que las normas sucesorias estaban expedidas para cumplirse, pero recurriendo a prácticas como las mencionadas, abiertamente se incumplen con ellas, dejando un mal precedente en la cultura de la legalidad. Otra consecuencia, es que se empuja con ésta prácticas a que no sea eficaz, la normatividad sucesoria, y se tenga tarde o temprano que reestructurar la institución de las sucesiones en nuestro Ordenamiento Civil peruano. 
Journal homepage: http://revistas.unap.edu.pe/rd/ E-mail: revistaderecho@unap.edu.pe

\section{LITERATURA CITADA.}

Armaza G. J.. (2001) 'Derecho sucesiones”. Parte General. Edit. Adrus. Arequipa.

Alexy R.T.. (1993) “Órdenes del Derecho”. Edit. Justus. Madrid. España.

Arias S. M.. (1996). “Exégesis”. Tomo II. Gaceta Jurídica Lima:. Perú.

Brugi, B. (1946) “Instituciones de Derecho Civil". Trad. de la cuarta ed. italiana por Jaime Simo Bofarull, México.

Bustamante, E. (2010) "Registro nacional de identificación Civil” Edit. Reus. Lima- Perú.

Calderón C. (2011) 'Observatorio del Derecho civil”. Volumen VI, Edit. Motivensa, Lima-Perú.

Castilllo, M. (2007) “La transferencia de propiedad inmueble en el Perú y la seguridad jurídica”. Edit. Palestra. Lima-Perú.

Carrión, E. (2008) "Derechos Sociales y Culturales" Ediciones de la PUCP. Ensayos interculturales. Lima. Perú.

Cervantes, D. (2002) "Manual de Derecho administrativo" Edit. IDEMSA. Lima. Perú.

Código Civil Comentado. (2004) Edit. Grijley. Edición sumillada y ampliada. Lima. Perú.

De la Puente, M. (1984) “El contrato en general”. Tomo I y II. Lima: PUCP. Perú.

Devis, H. (1938) Simulación. "Nulidad. Inexistencia de las sucesiones", en Rev. Jurídica, órgano de la Sociedad Jurídica de la Facultad Nacional de Derecho, año XXX, No 247 y 248, Bogotá, Colombia.

Forno, H. (1993) "El contrato con efectos reales". Ius et Veritas. Lima, Perú. año 4, nº 7.

Ferrero, A. (1985) "Derechos de Sucesiones". Edit. JV. Lima. Perú.

Ferrara, F. (1926) "La simulación de los negocios jurídicos", Madrid, España.

Legaz, L. (1979) 'Filosofía del Derecho". Edit Universo. Mexico.

Santoro, F. (1964) 'Doctrinas generales del Derecho civil”, Madrid.

Ramos, C. (2004) "Como hacer una tesis de Derecho y no morir en el intento”. Edit. Grijley 5ta. Edición. Lima. Perú.

Torres, M. (2002) "Estudios sobre el contrato de compraventa”. Lima: Grijley. Lima- Perú.

Varios. (2005) “Nuevas tendencias del Derecho Civil”. Varios. Edit. San Marcos. Lima. Perú. 